Thelma Bates, Department of Radiotherapy and Oncology, St Thomas's Hospital, and Dr Joan Davies, Public Health Laboratory Service, St Luke's Hospital, Guildford, for their advice and cooperation.

Requests for reprints should be sent to JEB.

\section{References}

1 Gardner, S D, et al, Lancet, 1971, 1, 1253.

2 Gardner, S D, British Medical fournal, 1973, 1, 77.

3 Mäntyjärvi, R A, et al, Annals of Clinical Research, 1973, 5, 283

- Portalani, M, et al, fournal of Medical Microbiology, 1974, 7, 543.

Shah, K V, Daniel, R W, and Warszawski, R M, fournal of Infectious Diseases, 1973, 128, 784

' Reese, J M, et al, Infection and Immunity, 1975, 11, 1375.

7 Gardner, S D, in Recent Advances in Clinical Virology, ed A P Waterson, p 95-115. Edinburgh, Churchill-Livingstone, 1977.

${ }^{8}$ Kristin, H, et al, Lancet, 1977, 1, 695.

- Kiessling, W R, et al, Lancet, 1977, 1, 324.

10 Connolly, J H, Haire, M, and Hadden, D S M, British Medical fournal, $1971,1,23$.

11 Alford, C A, American Journal of Diseases of Children, 1965, 110, 455

12 Bellanti, J A, et al, American Fournal of Diseases of Children, 1965, 110, 464.

13 Hanshaw, J B, Steinfeld, H J, and White, C J, New England fournal of Medicine, 1968, 279, 566.

14 Reynolds, D W, et al, New England fournal of Medicine, 1974, 290, 291.

15 Nagington, J, Fournal of Hygiene, 1971, 69, 645.

16 Jung, M, et al, Archives of Virology, 1975, 47, 39.

17 Pattison, J R, Mace, J E, and Dane, D S, fournal of Medical Microbiology, 1976, 9, 355 .

18 Best, J M, Banatvala, J E, and Watson, D, Lancet, 1969, 2, 65.

19 Caul, E O, Smyth, G W, and Clarke, S K R, fournal of Hygiene, 1974, 73, 329.

${ }^{20}$ Hamparian, V V, Muller, F, and Hummeler, K, fournal of Immunology, $1958,80,468$

21 Brady, M I, and Furminger, I G S, fournal of Clinical Microbiology, $1976,3,524$

22 Krech, U, personal communication, 1976.

${ }^{23}$ Almeida, J D, Brown, F, and Waterson, A P, fournal of Immunology, 1967, 98, 186

24 Penney, J B, and Narayan, O, Infection and Immunity, 1973, 8, 299.
${ }^{25}$ Schluederberg, A, Nature, 1965, 205, 1232.

${ }^{26}$ Schmidt, N J, Lennette, E H, and Dennis, J, fournal of Immunology, $1968,100,99$.

${ }^{27}$ Brown, G C, Baublis, J V, and O'Leary, T P, fournal of Immunology $1970,104,86$

${ }^{28}$ Ogra, P L, et al, New England fournal of Medicine, 1968, 279, 893.

29 Banatvala, J E, Best, J M, and Waller, D K, Lancet, 1972, 1, 1205.

${ }^{30}$ Al-Nakib, W, Best, J M, and Banatvala, J E, Lancet, 1975, 1, 182.

31 Pattison, J R, Dane, D S, and Mace, J E, Lancet, 1975, 1, 185.

22 Ishii, K, Matsunaga, Y, and Kono, R, fournal of Immunology, 1968, 101, 770.

${ }^{33}$ Edelman, R, et al, American fournal of Tropical Medicine and Hygiene, $1976,25,733$.

${ }^{34}$ Ross, C A C, and McDaid, R, British Medical fournal, 1972, 4, 522.

${ }^{35}$ Nahmias, A J, and Roizman, B, New England fournal of Medicine, 1973, 289, 719.

${ }^{36}$ Svehag, S E, and Mandel, B, fournal of Experimental Medicine, 1964, 119, 1 .

37 Svehag, S E, and Mandel, B, fournal of Experimental Medicine, 1964 $119,21$.

${ }^{38}$ Humphrey, J H, and White, R G, Immunology for Students of Medicine. Oxford, Blackwell, 1970.

39 Coleman, D V, Gardner, S D, and Field, A M, British Medical fournal, 1973, 3, 371

${ }^{40}$ Lecatsas, G, et al, Nature, 1973, 241, 343.

41 Takemoto, K K, et al, fournal of the National Cancer Institute, 1974, 53, 1205.

42 Padgett, B L, and Walker, D L, fournal of Infectious Diseases, 1973, 127, 467.

${ }^{43}$ Narayan, O, and Weiner, L P, Infection and Immunity, 1974, 10, 173.

44 Padgett, B L, et al, Lancet, 1971, 1, 1257.

45 Spencer, E S, and Anderson, H K, British Medical fournal, 1970, 3, 251.

46 Craighead, J E, Hanshaw, J B, and Carpenter, C B, fournal of the American Medical Association, 1967, 201, 725.

47 Fiala, M, et al, fournal of Infectious Diseases, 1975, 132, 421.

48 Simmons, R L, et al, Annals of Surgery, 1974, 180, 623.

49 Spencer, E S, and Andersen, H K, Acta Medica Scandinavica, 1972, 191, 107.

50 Strauch, B, et al, Lancet, 1974, 1, 234.

51 Nagington, J, Cossart, Y E, and Cohen, B J, Lancet, 1977, 1, 558.

52 Pattison, J R, and Mace, J E, fournal of Clinical Pathology, 1975, 28, 377.

\title{
Femoral vein thrombosis and total hip replacement*
}

\author{
J D STAMATAKIS，V V KAKKAR，S SAGAR，D LAWRENCE，D NAIRN，P G BENTLEY
}

British Medical fournal, 1977, 2, 223-225

\section{Summary}

Of 160 patients who underwent total hip replacement, 81 developed venographic evidence of thrombi in the operated leg. In 46 cases $(57 \%)$ the thrombus originated from the femoral vein, and in 43 of these the exact site of origin was defined by venography. In 34 cases $(74 \%)$ the thrombus arose from the wall of the femoral vein at the level of the lesser trochanter. This region was studied by intraoperative venography in eight patients undergoing total hip replacement, and in every case severe distortion of the common femoral vein was observed, producing almost total occlusion.

We suggest that intraoperative damage to the femoral *Based on a paper presented to the Surgical Research Society of Great Britain and Ireland on 3 July 1976 at Edinburgh.

King's College Hospital Medical School, London SE5 8RX

J D STAMATAKIS, FRCS, MRC research fellow

V V KAKKAR, FRCS, professor of surgical science and director of thrombosis research unit

S SAGAR, FRCS, surgical research fellow

D LAWRENCE, FRCS, surgical research fellow

D NAIRN, FRCS, senior orthopaedic registrar

P G BENTLEY, FRCS, surgical research fellow vein results from manipulation of the leg, and that this is one reason why the operation is followed by a high incidence of deep vein thrombosis in the upper femoral region.

\section{Introduction}

Total replacement of the hip joint has become increasingly popular recently. Nevertheless, prospective studies, using the ${ }^{125}$ I-fibrinogen test and ascending venography, have shown that it is associated with a high incidence of thromboembolic complications. ${ }^{1-5}$ Furthermore, necropsy studies on patients dying in the postoperative period indicate that pulmonary embolism is the most common cause of death after this operation. ${ }^{6-8}$ Many factors contribute to deep vein thrombosis (DVT) in these high-risk patients. ${ }^{9}$ The distribution of venous thrombi in 81 patients with venographically evident DVT after total hip replacement suggested that a thrombogenic stimulus existed in the region of the proximal femoral vein in the operated leg. We studied this further by visualising the femoral vein intraoperatively by means of ascending venography.

\section{Patients and methods}

One hundred and sixty patients who underwent total hip replacement were studied for postoperative DVT. All gave written, informed 
consent. Eighty-one developed venographically proved thrombosis in the operated leg, and these patients form the basis of this report. All patients were also in concurrent trials to assess the efficacy of heparin, dihydroergotamine, and routine physiotherapy in preventing postoperative venous thrombosis. The results of these studies are reported elsewhere. ${ }^{510}$

Postoperative ascending venography-Postoperative DVT was diagnosed by ascending venography in every case with use of a technique described elsewhere. ${ }^{11}$ Acute thrombosis was diagnosed according to the following criteria: a filling defect in an otherwise well-opacified vein that remained unchanged on two successive radiographs; partially occluding thrombi seen as well-defined translucent areas surrounded by a rim of contrast medium; completely occluding thrombi with a collateral circulation.

Intraoperative ascending venography was performed while the hip joint was exposed for insertion of the prosthesis, a technique similar to that of postoperative ascending venography being used. A 21-gauge butterfly needle was inserted into a dorsal vein in the foot and connected by an extension tube to a syringe for injection of contrast medium (Angiografin). A transparent sterile drape was placed over the foot, covering the needle and part of the tube. The operation then began. Before venography, a tourniquet was placed around the ankle to direct contrast medium into the deep veins of the calf, and another around the lower thigh to retain the medium within the calf veins; $25 \mathrm{ml}$ of contrast medium was injected through the butterfly needle, and radiographs of the upper femoral vein were taken immediately after releasing the upper tourniquet. An adequate bolus for visualising the femoral vein was obtained by squeezing the calf the moment the upper tourniquet was released. Radiographs were taken of the proximal femoral vein before dislocating the hip, and then after dislocation with the limb held in the position attained during exposure of the joint. With the lateral approach the limb is severely adducted at the hip, and with the posterior approach it is internally rotated through almost $100^{\circ}$.

\section{Results}

\section{DISTRIBUTION OF POSTOPERATIVE DEEP VEIN THROMBI}

The site and extent of the venographic thrombi in the 81 patients was defined as limited to the calf, continuous within the calf and femoral vein, discontinuous within the calf and femoral vein, or confined to the femoral vein (fig 1).

In 19 patients $(23.5 \%)$ thrombus was found only in the femoral veins, and in the remaining $62(76.5 \%)$ it was found in the calf with or without associated femoral vein thrombus. In 32 of these 62 patients the thrombus was confined to the calf veins, but in 24 there was associated thrombus in the femoral vein that was discontinuous from the calf thrombus and must therefore have arisen independently from within the femoral vein. Moreover, among the remaining six patients, all of whom had thrombus extending in continuity from the calf to the femoral vein, venography performed earlier in the post-
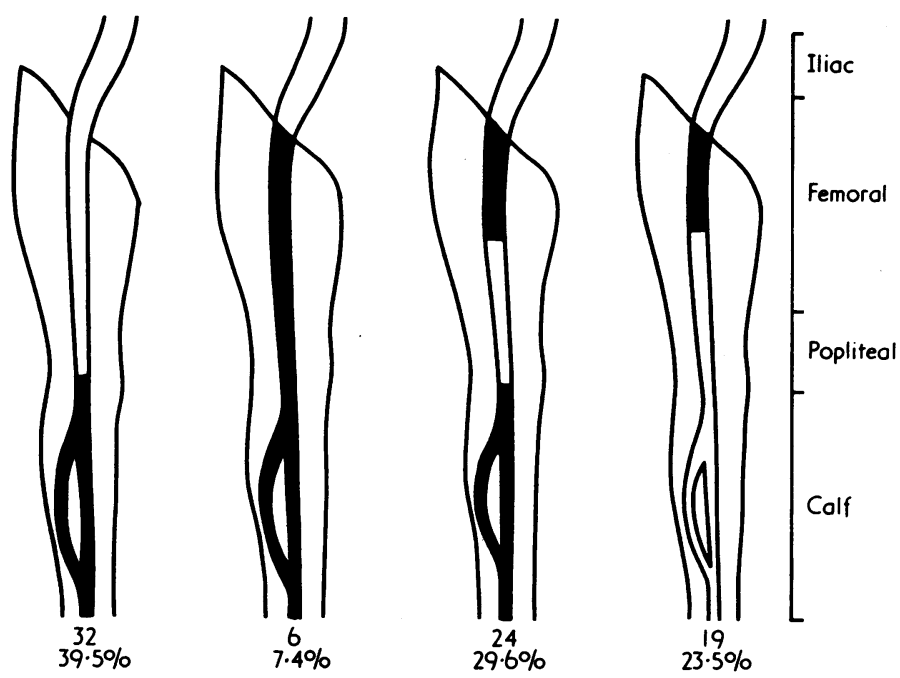

FIG 1-Distribution of DVT in operated limb in 81 patients after total hip replacement.
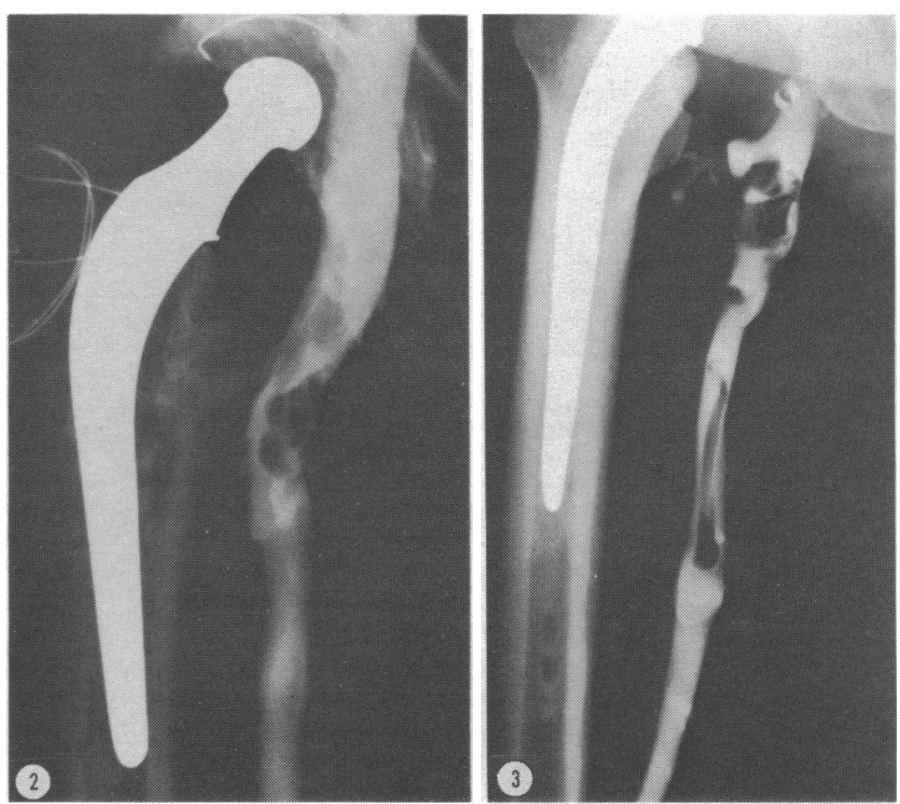

FIG 2-Ascending venogram showing valve cusp thrombus in proximal femoral vein after total hip replacement.

FIG 3-Ascending venogram showing floating thrombus arising from valve cusp in mid-femoral region together with more-proximal cusp thrombi.

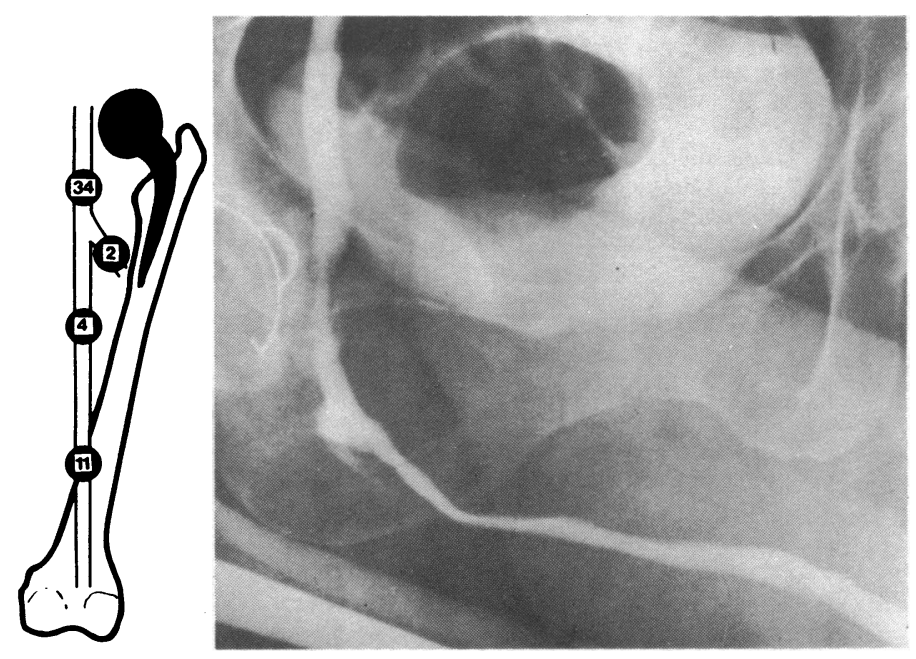

FIG 4-(left) Diagrammatic representation of sites of origin of 51 femoral vein thrombi in 43 patients after total hip replacement.

FIG 5-(right) Intraoperative venogram showing proximal femoral vein during total hip replacement using lateral approach.

operative period had shown in three of them that the femoral vein thrombus had formed within that vein and not by proximal extension of calf thrombus. Thus in $\mathbf{4 6}$ patients venography showed a femoral vein origin for the thrombus.

The exact site of origin was identified either as a cusp thrombus (figs 2 and 3 ) or as a larger thrombus floating freely in the femoral vein and anchored at its most distal part (fig 3). There were multiple sites of origin of femoral vein thrombi, but these fell into one of four groups (fig 4). Uncommon sites were the profunda femoris (two patients) and mid-superficial femoral veins (four patients). A more frequent site of origin was a valve cusp at or just above the adductor hiatus (11 patients). By far the most common site of origin, however, was the valve cusp or wall of the femoral vein in the region of the lesser trochanter (34 patients).

\section{INTRAOPERATIVE VENOGRAPHY}

Intraoperative venography was performed on eight patients. In four the hip was exposed by the lateral approach, ${ }^{12}$ and in four by the 
posterior approach. Radiographs showed distortion of the upper femoral vein in every case during the time that the joint was dislocated and the limb manipulated for insertion of the prosthesis. In each case in which the lateral approach was used the femoral vein appeared angulated and narrowed, the maximum distortion being at the level of the lesser trochanter (fig 5). With the posterior approach, each case showed the femoral vein to be narrowed at the level of the lesser trochanter, the appearances being that of torsion (fig 6). In both operative positions the long saphenous vein often filled with contrast medium on venography, whereas before dislocation of the hip this did not occur.

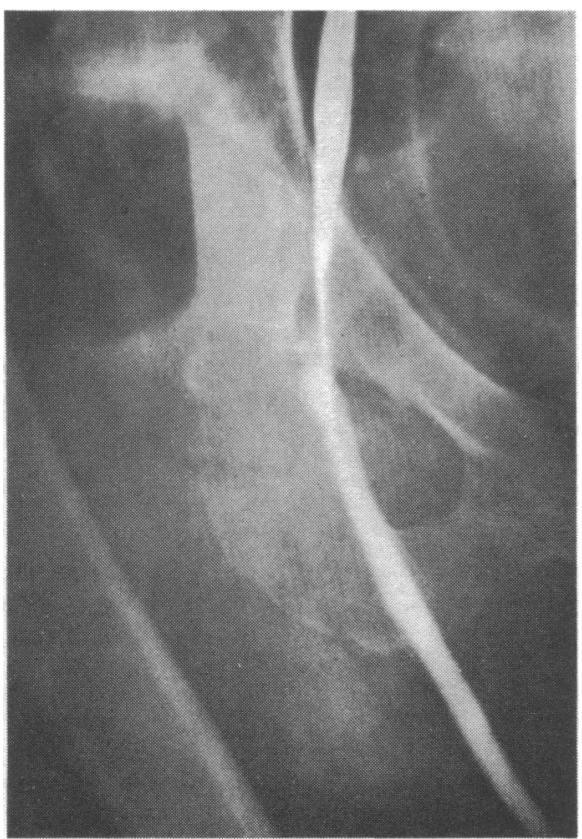

FIG 6-Intraoperative venogram showing proximal femoral vein during total hip replacement using posterior approach.

\section{Discussion}

The most striking feature of this study was the high incidence of thrombi arising from the proximal vein after total hip replacement. Previous studies, which have not included patients undergoing this operation but which have used ascending venography to demonstrate DVT, have indicated that the proximal femoral vein is an unusual site for the origin of venous thrombi. ${ }^{13-15}$ In these studies most femoral vein thrombi were continuous with coexisting calf thrombus. The incidence of continuous tibial-femoral venous thrombosis in our study was low because calf thrombi were detected early by means of the ${ }^{125}$ I-fibrinogen test, and extending thrombi within the tibial and popliteal veins were promptly treated with anticoagulants to prevent propagation into the femoral vein. Several workers have suggested that most major venous thrombi arise within the femoral vein itself, the calf veins becoming involved by distal propagation of thrombus. ${ }^{16} 17$ These workers base their conclusions on necropsy studies, thereby investigating a highly selected group of patients whose disease terminates in death. The necropsy findings-namely that many major venous thrombi originate from proximal major (femoral and iliac) veins -are not confirmed by isotopic ${ }^{1819}$ or venographic ${ }^{13-15}$ studies on living patients. These show that such thrombi usually result from proximal extension of a primary calf thrombus.

Our findings, however, show that, unlike other groups studied, patients undergoing total hip replacement frequently develop primary femoral vein thrombi without concomitant calf clot. Furthermore, in an earlier series from our unit, in which the same techniques of venography and the fibrinogen uptake test were used for 50 patients undergoing hip surgery for fracture of the femoral neck, ${ }^{20} 27$ patients $(54 \%$ ) developed postoperative DVT in the injured limb, all confirmed by venography, but in none were thrombi found to originate primarily from the femoral vein. This finding has implications for the aetiology of postoperative thrombi in patients who undergo total hip replacement.

The presence of thrombi in the proximal femoral vein seems to support the theory of local thrombogenic stimuli peculiar to the operation of total hip replacement. Two such stimuli may be considered: thermal, from curing of the methylmethacrylate cement; and mechanical, due to local surgical manipulation. We investigated the second concept by visualising the femoral vein during surgery by means of ascending venography with the limb held in the dislocated position. The findings were consistent with both the lateral and posterior approaches, there being a local deformity in the proximal femoral vein. Furthermore, when the limb was internally rotated or severely adducted there was filling of the long saphenous vein. This may be interpreted as reflecting a degree of venous obstruction in the operated limb. Many studies have shown that total hip replacement is followed by a high incidence of postoperative DVT, particularly in the operated leg, and thus intraoperative venous stasis may be of considerable importance.

The problem of local thermal stimulus remains to be studied. A burn of the femoral artery by methylmethacrylate cement has been described in two cases, both of which required surgical repair of the damaged arterial segment. ${ }^{21}$ This type of lesion must be rare but indicates the possibility of less overt damage to the femoral vein, which warrants further investigation.

Our findings show that after total hip replacement there is an unusually high incidence of femoral vein thrombi, particularly in the proximal part of the vein. One reason for this phenomenon may be intraoperative distortion of the vessel with resultant local damage, and the high overall incidence of venous thrombi might be associated with an unusual degree of intraoperative venous stasis.

We thank the orthopaedic consultants of King's College Hospital for permission to study patients under their care.

We are grateful to Miss V P Ward for her help, the radiographers of King's and St Giles's, Mrs J Brazier for technical work, and Mrs S Docksey for secretarial help.

The study was supported by the Medical Research Council (Programme Grant No G937/756) and the King's College Hospital Research Trust.

\section{References}

1 Evarts, C M, and Feil, E, fournal of Bone and foint Surgery, 1971, 53A, 1271.

${ }^{2}$ Harris, W H, et al, fournal of Bone and foint Surgery, 1974, 56A, 1552

${ }^{3}$ Hampson, W G, et al, Lancet, 1974, 2, 795.

4 Morris, G K, Henry, A P J, and Preston, B J, Lancet, 1974, $2,797$.

5 Sagar, S, et al, Lancet, 1976, 1, 1151.

6 Crawford, W J, Hillman, F, and Charnley, J, internal publication No 14 Centre for Hip Surgery, Wrightington Hospital, 1968.

${ }^{7}$ Coventry, M B, Nolan, D R, and Beckenbaugh, R D, fournal of Bone and Foint Surgery, 1973, 55A, 1487.

${ }^{8}$ Rothmerl, J E, Wessinger, J B, and Stichfield, F E, Archives of Surgery, 1973, 106, 135 .

-Wessler, S, in Prophylactic Therapy of Deep Vein Thrombosis and Pulmonary Embolism, ed J Fratantoni and S Wessler, p 173. Washington, DHEW publication No (NIH) 76-866, 1976.

10 Stamatakis, J D, et al. Submitted for publication.

11 Kakkar, V V, Milbank Memorial Fund Quarterly, 1972, 50, 206.

12 Charnley, J, Lancet, 1961, 1, 1129.

13 Bauer, G, Acta Chirurgica Scandinavica, 1940, suppl No 61, p 84.

14 Nicolaides, A N, et al, British fournal of Radiology, 1971, 44, 653.

15 Stamatakis, J D, et al. Submitted for publication.

16 Sevitt, S, and Gallagher, N G, British fournal of Surgery, 1961, 48, 475.

${ }_{17}$ Aschoff, L, Lectures in Pathology. New York, Hoeber, 1924.

18 Kakkar, V V, et al, Lancet, 1969, 2, 230.

19 Nicolaides, A N, and O'Connell, J D, in Thromboembolism, ed A N Nicolaides, p 167. Lancaster, Medical and Technical Publishing, 1975. 20 Field, E S, et al, British fournal of Surgery, 1972, 59, 377.

21 Taylor, G, personal communication.

(Accepted 20 May 1977) 